\title{
A DESSEGREGAÇÃO RACIAL NOS EUA: UM RETORNO ÀS “REFLEXÕES SOBRE O LITTLE ROCK" DE HANNAH ARENDT
}

\author{
RACIAL DESSEGREGATION IN THE USA: A RETURN TO \\ “REFLECTIONS ON LITTLE ROCK” BY HANNAH ARENDT
}

Izaquiel Arruda Siqueira ${ }^{1}$

\begin{abstract}
RESUMO
O presente ensaio trata-se de um percurso sobre um texto da filósofa alemã, Hannah Arendt, intitulado de Reflexões sobre o Little Rock. Nele, Arendt reflete sobre o processo de dessegregação nos Estados Unidos da América, a partir da lei que permitiu o ingresso de crianças negras nas escolas secundárias, onde só era permitida a frequência de alunos de cor branca. Acreditando na necessidade de, primeiramente, acabar com a dessegregação a partir da autorização do casamento civil entre pessoas negras e brancas, a filósofa polemizou ao explicitar sua opinião sobre o que estava acontecendo nas escolas da pequena cidade de Little Rock. Tendo sido mal interpretada, a preocupação de Arendt estava fundada na criança e sua necessidade de proteção, para que o mundo não a destrua (e tampouco, a mesma destrua o mundo). A partir de sua crítica, nos deixou uma lição: a capacidade de amar o mundo não nos desautoriza da responsabilidade de cuidar, proteger e apresentar este mesmo mundo aos novos e aos jovens. E esta capacidade de amar nos coloca diante da experiência de assumirmos nossos próprios feitos e, politicamente, resolvermos os conflitos que afetam nossas relações enquanto homens.
\end{abstract}

Palavras-chaves: Dessegregação racial; Hannah Arendt; EUA; Little Rock.

\begin{abstract}
This essay explores a text by the German philosopher Hannah Arendt titled Reflections on Little Rock. Arendt reflects on the desegregation process in the United States of America, based on the law that allowed black children to attend secondary schools where before only white students were allowed. Believing in the need to end the desegregation after the authorization of the civil marriage between blacks and whites, the philosopher generated a polemic when she expressed her opinion about what was happening in Little Rock schools. She was misunderstood, as Arendt's concern was founded on the child's need for protection so that the world does not destroy them (nor do they destroy the world). Based on her criticism, she taught us that the capacity to love the world does not deprive us of the responsibility to care for, protect, and present this same world to youth and young people. Moreover, this capacity to love puts us before the experience of assuming our deeds and, politically, resolving the conflicts that affect our relationships as humankind.
\end{abstract}

Keywords: Racial desegregation; Hannah Arendt; USA; Little Rock.

\footnotetext{
1 Doutorando e Mestre em Educação (PPGEDu/CE/UFPE). Especialista em Filosofia da Educação (PGFILE/UEPB). Graduado em Pedagogia (UNINTER) e Filosofia (FAFICA). Professor do Centro de Ensino Superior Santa Cruz (CESAC). e-mail: izarsiq@gmail.com
} 


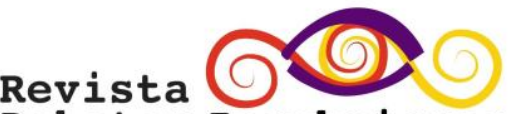 \\ Debates Insubmissos}

Os acontecimentos que marcam nossas vidas dizem muito de nós, e nós podemos dizer muito deles através do ato de narrar. Narram-se vidas, fatos e histórias. Sem a narrativa, não se estabelece um mundo de sentidos entre os homens e mulheres. Narrar é, de alguma maneira, interpretar. É usar da hermenêutica, extraindo significados. Por isso, antes de adentramos na polêmica narrada por Hannah Arendt, queremos narrar um pouco de sua vida, para que saibamos da impossibilidade de uma legitimação racista por parte da filósofa. Não é uma defesa dela. Talvez seja a vontade de buscar uma compreensão e não engrossar a fila dos que falam demais por não ter nada a dizer, como cantou Renato Russo (1986).

A pensadora Hannah Arendt foi uma filósofa alemã que nasceu no início do século XX, em 14 de outubro de 1906. De uma família de judeus assimilados, não praticantes, desde cedo conheceu o desprezo por ser quem era, uma judia. Em casa, foi advertida por sua mãe a não aceitar insultos contra sua identidade judaica. O conselho era: quando os professores fizerem comentários antissemitas, não se humilhe, defenda-se! Levante-se e venha para casa! (YOUNG-BRUEHL,1997). Elizabeth Young-Bruehl, sua biógrafa, nos diz:

Certa vez, Hannah Arendt voltou da escola primária perguntando à mãe se era verdade o que uma de suas colegas dissera - que seu avô havia assassinado o Senhor Jesus. Quando, já adulta, refletiu sobre tais incidentes - e falou a respeito deles numa entrevista de televisão em 1964 -, colocou-os num contexto que minimizava a sua agressividade mas destacava o que deles havia aprendido. (YOUNG-BRUEHL, 1997, p. 33).

Todavia, a fase mais difícil de sua vida veio quando adulta: Adolf Hitler se tornou chanceler da Alemanha. Quatro semana depois, aconteceria o incêndio do Parlamento Alemão, o Reichstag, e uma série de atos antijudaicos e prisões começaram a acontecer. $\mathrm{O}$ comunismo foi satanizado e deu-se início à uma nova Alemanha, a Alemanha nazista. A política, junto ao espaço público, entrou numa lógica de esgarçamento, onde se instalou um regime totalitário.

A jovem acadêmica Arendt não acreditava no que estava acontecendo. E, pouco tempo depois, passou a ser alvo, inimigo comum, dos detratores nazistas: na primavera de 1933 foi presa pela Gestapo e liberada oito dias depois, fugindo da Alemanha e se tornando uma apátrida. E foi nessa condição de alguém (ou a experiência do "ninguém”) que não tem 


\title{
Revista \\ Debates Insubmissos
}

"direito a ter direitos", que se alinhou a organizações sionistas que para ajudar jovens refugiados judeus a emigrarem para o território da Palestina. Sete anos depois, em maio de 1940, foi presa e enviada para um campo de internamento de pessoas consideradas “estrangeiras inimigas” e “indesejáveis” em Gurs, na França.

Neste campo de internamento, Arendt conseguiu escapar e fugir para os Estados Unidos, onde viveu alguns anos na condição de apátrida até 1951, quando ganhou cidadania estadunidense. E foi lá onde começou uma intensa atividade como teórica política, escrevendo obras importantes para entendermos o século XX e lançarmos luzes sobre o que vivemos hoje. Suas obras mais famosas são: “Origens do totalitarismo², Entre o passado e o futuro $^{3}$ e A condição humana ${ }^{4}$.

Antes de entrarmos no debate sobre os acontecimentos que se deram em Little Rock, é importante a percepção da liberdade do pensamento e da opinião de Hannah Arendt. Esta liberdade lhe deu condições de não se prender ou deixar-se amarrar às correntes teóricas clássicas e cristalizadas, que tendem a dar sempre as mesmas respostas a problemas diferentes. Se quisermos situar Arendt à direita, nos equivocaremos. Se quisermos situá-la à esquerda, também no equivocaremos. Talvez seu lugar, enquanto pensadora, esteja dentro mesmo do movimento filosófico - que é desconfiado -, ainda que ela tenha negado a alcunha de filósofa. Young-Bruehl (1997, p. 278) nos diz:

\begin{abstract}
Hannah Arendt raramente retinhas suas opiniões, fosse por razões pessoais ou políticas; qualquer Schwindel ("lorota"), não importa quão bem intencionada, deixava-a incomodada. Quando era prudente, em geral mais tarde pagava caro, e com algum tipo de soco no nariz. O fim da sua paciência era o começo dos problemas, pois saía de seus silêncios intempestivamente, cortante, falando no tom de "isso se refere a você" de suas antigas colunas do Aufbau. Mas seus comentários mais pungentes eram reservados para temas sobre os quais os outros se mantinham em silêncio por razões que ela não podia aceitar. Sempre que suspeitava de uma conspiração de silêncio, escrevia furiosa e às vezes com desdém.
\end{abstract}

Pois bem, esta é Arendt, a pensadora que não temia o dissenso. Que não se isentava de dar sua opinião, inclusive, em relação à educação, mesmo nunca tendo criado uma teoria

\footnotetext{
2 Publicação original em 1949.

${ }^{3}$ Publicação original em 1954.

${ }^{4}$ Publicação original em 1958
} 


\section{Revista \\ Debates Insubmissos}

pedagógica. Suas produções são, geralmente, trabalhos sobre questões que atravessavam a sociedade. Deste modo, seu primeiro texto referente à educação, foi "Reflexões sobre o Little Rock", que ficou pronto em 1957. Porém, por problemas de publicação só veio a público em 1959. O mesmo, trata-se de uma crítica pontual à lei de integração de crianças negras nas escolas do sul dos Estados Unidos da América, especificamente, na cidade de Little Rock, no estado de Arkansas.

Neste ensaio, a autora não tem por finalidade discutir a educação em si, mas discutir um problema ligado à esfera social ${ }^{5}$ que veio a se tornar político. A feitura do texto se deu após Arendt ter ficado indignada com cenas de agressão à uma menina negra numa escola desta cidade, por causa da dessegregação forçada e legitimada por lei. Young-Bruehl, relata as intenções da autora ao escrever:

Solidária, escreveu pelos estudantes negros que tinham que suportar o ódio racial dos brancos sulistas e pelas vítimas judias da perseguição nazista; e a partir dessa irritação moral, escreveu contra pais negros que permitiram que seus filhos carregassem o fardo de uma luta racial e contra líderes judeus que "cooperaram" com os nazistas. Enquanto escrevia, Arendt apresentou a si mesma uma pergunta pessoal: o que você teria feito? Mas, em ambos os casos, a pergunta foi feita e respondida nos bastidores; sua tentativa empática, ou seja, colocar-se no lugar de outros e pensar as alternativas de ação, precedia seu escrever; mas a falta desse questionamento tornou seu texto arrogante e rude, além de incorreto em sua avaliação para muitos leitores. (YOUNG-BRUHEL, 1997, p. 278).

\footnotetext{
5 Adriano Correia, efetivando a reflexão feita por Arendt em "A Condição Humana" (2014) sobre o social, diz que: "A esfera social é 'o domínio curiosamente híbrido no qual os interesses privados adquirem significação pública'. O que caracteriza a modernidade política é a compreensão da política como uma função da sociedade, com a implicação fundamental de que as questões eminentemente privadas da sobrevivência e da aquisição transformaram-se em interesse "coletivo", ainda que nunca se pudesse conceber de fato tal interesse como sendo público. $\mathrm{O}$ advento de uma esfera híbrida como a social teria promovido uma indistinção ente os domínios público e privado e o deslocamento de princípios e propósitos de uma esfera a outra, constituindo-se como uma intersecção a minar as possibilidades de felicidade pública ou privada. Com efeito, diz Hannah Arendt, 'a busca irresponsável por interesses privados na esfera público-política é tão prejudicial ao bem público quanto a arrogante tentativa dos governos de regular a vida privada'. Ela julga que o social, as questões privadas em sua dimensão coletiva (ainda que com implicações políticas), não constitui um espaço próprio, terceiro em relação ao público e o privado. O social seria um câncer, que expande seu espaço na medida em que se espraia sobre o privado e o público (CORREIA, 2014, p. 134). Trata-se de um modo diferente de ver o social, diferente do que estamos acostumado a ver, geralmente partindo do senso comum.
} 


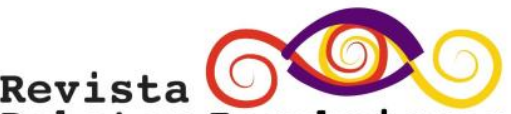 \\ Debates Insubmissos}

O fato mesmo, é que a pequena Little Rock tornou-se famosa em 1957 pela polêmica em torno dos acontecimentos referentes à sua principal escola, a Central High School. Mas, antes disso, a segregação das pessoas negras já havia sido declarada inconstitucional pela Suprema Corte dos EUA, em 1954 e, no ano seguinte, o conselho de educação (School Board) de Little Rock havia decidido que o processo de dessegregação começaria em 1957 pelas escolas secundárias. Porém, a consumação deste fato gerou muito tumulto, incompreensões e inconformações, uma vez que, mesmo com a permanência das escolas para negros/as, a partir de agora, estes/as poderiam frequentar as escolas para os/as brancos/as.

Assim, para o ingresso nesta escola, foram submetidos a um duro processo seletivo dezessete alunos/as negros/as, entre os/as quais oito desistiram de suas vagas já no início do ano letivo, restando apenas nove, que são lembrados/as como os heroicos Little Rock Nine (Os Nove de Little Rock, em tradução livre). São lembrados/as desta forma por terem suportado uma série de agressões, expurgos e toda sorte de preconceito por parte dos/as outros/as alunos/as e, inclusive, dos pais e mães inconformados com esta abertura da escola para aqueles/as “de cor". Sobre o acontecido, a jornalista Rachel Gessat cita o jornal The New York Times, que informou da seguinte maneira na época:

\footnotetext{
Uma turba de manifestantes em pé de guerra, aos berros histéricos, obrigou hoje nove escolares negros a deixarem a Central High School. Apesar da presença de um grande número de policiais locais e estatais para proteger os negros contra ataques, essas forças policiais acabaram desistindo em face da fúria de cerca de mil manifestantes brancos e, por volta do meio-dia, ordenaram aos alunos negros que deixassem a escola. A tentativa de integração durou 13 minutos. Os negros foram escoltados pela polícia através da turba e levados para suas casas, sem serem feridos. (NYT, 2017 apud GESSAT, 2017).
}

De forma inescrupulosa, os/as jovens foram barrados pela Guarda Nacional enviada pelo governador do Arkansas, Orval E. Faubus, no primeiro dia de aula, com a alegação de manter a ordem pública (o que era uma farsa, já que Faubus era contrário à integração). Os/as nove alunos/as somente tiveram acesso à escola semanas depois, quando o presidente do país, Dwight Eisenhower, colocou todas as unidades policiais e militares do Estado de Arkansas sob o comando do Governo Federal, enviando mil homens da 101 a Divisão para Little Rock a fim de dispersar os/as manifestantes. Assim, cada aluno/a do grupo dos nove, 


\section{Revista \\ Debates Insubmissos}

recebeu um guarda-costas, mantendo guarda à porta da sala de aula para que, diante de todo este alvoroço discriminatório, no dia 25 de setembro de 1957, conseguissem participar de um dia inteiro de aulas na Central High School (GESSAT, 2017).

No ínterim dessa confusão, Hannah Arendt viu na imprensa uma foto de uma adolescente negra sendo hostilizada na saída da escola, protegida por um homem branco, amigo de seu pai, e ficou indignada pela situação, como já dissemos. Young-Bruehl descreve a indignação de Arendt:

O "pai ausente" fizera o que nenhum pai deveria fazer: pedira à filha para estar onde não era desejada, comportar-se como uma parvenu, tratar a educação como um meio de avanço social. A criança não recebeu a "proteção absoluta da dignidade" que Martha Arendt outrora havia dado tão conscientemente à filha, que fora instruída a deixar as situações sociais em que não fosse desejada e ir para casa. (YOUNG-BRUHEL, 1997, p. 281).

Para a filósofa, de alguma maneira, as crianças estavam pagando o preço das questões sociais criadas pelos adultos e que, eles próprios, não suportariam pagar nem resolver no âmbito público. É evidente que, neste escrito, a autora desenvolve uma instigante reflexão, capaz de mobilizar o nosso pensamento a respeito da responsabilidade dos adultos para com as crianças neste mundo comum ${ }^{6}$, no qual, os primeiros têm uma dupla missão no trato com os segundos (os novos e os recém-chegados): protegê-los deste mundo e, no mesmo movimento, proteger o mundo deles.

Arendt recebeu diversas críticas por ter tocado em pontos delicados, dos quais desconhecia em sua integralidade. É inegável que ela não avançou nas questões que diziam respeito às conquistas do Movimento Negro, alegando que deveria ter sido melhor lutar, primordialmente, para se ter direito ao voto nos estados do sul dos EUA e sobre a mudança nas leis de casamento interracial, já que as pessoas negras não podiam casar com as brancas.

ela argumentou que o sancionamento legal da segregação na esfera privada "[não] governada nem pela igualdade [dentro da lei], nem pela discriminação [social], mas pela exclusividade", isto é, por escolha pessoal, individual - era o tipo

\footnotetext{
${ }^{6}$ Para Arendt, o mundo comum não pode ser, exclusivamente, caracterizado por aquilo que está a nossa volta, mas é, também, um espaço construído pelo nosso trabalho e constituído pela ação (ALMEIDA, 2011).
} 


\title{
Revista \\ Debates Insubmissos
}

mais abominável de segregação sancionada. Arendt, cujo casamento com um nãojudeu nunca poderia ter ocorrido em sua pátria enquanto vigoravam as leis de Nuremberg, sentia que as leis contra os casamentos inter-raciais, que em 1959 existiam em 29 dos 49 estados, deveriam ser a primeira frente de ação. (YOUNGBRUHEL, 1997, p. 280).

Isto não quer dizer que ela era contra a dessegregação escolar. Para ela, qualquer discriminação pública seria inaceitável. A questão é que o ponto crucial da integração educacional, estava assentado no uso improdutivo e politicamente arriscado da lei para se combater os preconceitos com proibições e outras intervenções, já que, é muito próprio dos regimes totalitários a pretensão de regular e, até mesmo, invadir todas as esferas da existência humana, inclusive, a vida privada (MORAES, 2017).

Para a autora, a lei não poderia ser usada para forçar uma convivência, pois, qualquer grupo social, étnico, etc., tinha direito de escolher com quem quer se associar; e os pais têm o direito privado sobre seus filhos, e o direito social à livre associação. Deste modo, o aspecto público e político da educação estaria voltado para os conteúdos da educação da criança e não, efetivamente, ao contexto da associação. A questão da dessegregação era, sobretudo, um problema que deveria ser resolvido no âmbito público, através da ação política, e não dentro do espaço escolar, através da educação (BODZIAK JÚNIOR, 2017).

\begin{abstract}
Colocar uma criança negra em um ambiente predominantemente branco seria submetê-la a uma situação humilhante, a qual poderia minar e comprometer sua integridade. Ademais, as políticas que forçavam a desintegração ao transformar os pátios das escolas em campos da disputa pela dessegregação, colocavam as crianças para resolver um problema dos adultos. A escola, para Hannah Arendt, não era o espaço de disputas políticas, pois “[...] não é de modo algum o mundo, e não deve fingir sê-lo; ela é, em vez disso, a instituição que interpomos entre o domínio privado do lar e o mundo com o fito de fazer com que seja possível a transição, de alguma forma da família para o mundo" (Arendt, 2007a, p. 238). Por isso, ela considerava ilusória a ideia rousseauísta de transformar a escola em um veículo de transformação do mundo, educando as crianças no espírito do futuro. Para ela, esta ideia é própria de governos tirânicos (Arendt, 2004, p. 265; 2007a, p. 225). Assim, a separação que Arendt coloca entre o social e político visaria a mostrar que a mudança nas condições dos próprios negros era uma questão política, e deveria encontrar resposta na ação política, não na educação. (BODZIAK JÚNIOR, 2017, p. 61).
\end{abstract}

Aqui é o ponto central em que Arendt sofreu diversas críticas, pois defendia que o governo não poderia forçar a integração nas escolas. Para ela, as instituições escolares pertenciam ao âmbito social. Neste espaço, não há igualdade, pois os homens não são livres 


\section{Revista \\ Debates Insubmissos}

como no espaço público onde se dá a política, que tem como sentido a liberdade. Esta liberdade - que é pública e plural - nasce quando se atravessa o reino da necessidade, saindo da privação. Além disso, a política se efetiva através das relações que os homens e mulheres podem empreender entre os seus iguais. Assim, era inconcebível que a criança estivesse dentro desse âmbito onde agem os adultos.

Para Arendt, é dentro do âmbito social onde subsiste a exclusão e inclusão como algo natural deste mesmo espaço. Aliás, a discriminação é algo muito próprio deste âmbito. Para ela, “a questão não é abolir a discriminação, mas como mantê-la confinada dentro da esfera social, quando é legítima, e impedir que passe para a esfera política e pessoal, quando é destrutiva" (ARENDT, 2004, p. 274). E, ainda, que a educação está sobreposta sobre os três âmbitos: o privado, o público e o social - algo que não vai afirmar no ensaio A crise na educação (2013). Neste texto, dirá que a escola está no âmbito pré-político, ou seja, aquele lugar entre (ou de transição) o lar e o âmbito público e que, sem agir politicamente em seu próprio espaço, pode honrar seu compromisso com o mundo (ALMEIDA, 2011). Refletindo sobre esta questão, Eduardo Jardim de Moraes nos diz:

Na esfera pública da política somos regidos pelo princípio da igualdade, já na vida em sociedade, em um contexto pré-político, somos diferentes uns dos outros e temos esse direito. É possível que preconceitos apareçam e se espalhem na vida em sociedade, gerando fortes tensões. (...) Dizer que preconceitos são legítimos na vida social, como acredita Hannah Arendt, não significa que ela os apoiasse. Ela afirmou que "do ponto de vista da pessoa humana, nenhuma dessas práticas discriminatórias faz sentido". Mas ela achava também que não devemos impedir que uma pessoa escolha se relacionar apenas com seus iguais e não com os diferentes dela. Pode ser uma escolha medíocre, mas temos que respeita-la. (MORAES, 2017).

Assim, tendo o artigo se tornado polêmico, recebeu várias críticas. Inclusive, críticas do escritor Ralph Ellison, que chegou a afirmar, em uma entrevista, que a posição de Arendt se referia ao fato de ela aplicar certos princípios à uma situação que desconhecia e que, uma das pistas importantes para o significado da experiência do negro residia no "ideal de sacrifício": as crianças teriam que passar por isso, já que, ao longo de suas vidas iriam encontrar diversas situações semelhantes de racismo e precisavam aprender, desde cedo, o 


\title{
Revista \\ Debates Insubmissos
}

que é o mundo e como ser um negro americano, sabendo domar seu medo e controlar sua raiva. Disse Ellison:

\begin{abstract}
Algumas pessoas aprendem mais sobre a natureza verdadeira daquela sociedade, mais sobre o verdadeiro caráter dos seus valores, do que aqueles que podem considerar assegurado o seu próprio lugar na sociedade. Elas podem não ser capazes de soletrá-lo filosoficamente, mas elas o agem... acredito que uma das pistas importantes para o significado da experiência do negro reside na idéia do ideal de sacrifício. O fato de Hannah Arendt não apreender a importância desse ideal entre os negros sulistas fez com que se desviasse para o campo da esquerda em seu "Reflexões sobre o Little Rock", no qual acusou os pais negros de explorar os filhos durante a luta para integrar as escolas. Mas ela não tem absolutamente nenhuma concepção do que se passa nas mentes dos pais negros quando mandam seus filhos através dessas linhas de pessoas hostis. E eles estão, no entanto, conscientes da sensação de um rito de iniciação que tais eventos efetivamente constituem para a criança, um confronto dos terrores da vida social com todos os mistérios desnudados. E na visão de muitos desses pais (que adorariam se o problema não existisse) espera-se que essa criança se defronte com o terror e contenha o seu medo e sua raiva precisamente por ser um negro americano. Assim, exige-se que ela domine as tensões internas criadas por sua situação racial, e se sair ferida - isso será mais um sacrifício. É uma dura exigência, mas se a criança falhar nesse teste básico sua vida será ainda mais dura. (ELLISON, 1965 apud YOUNGBRUEHL, 1997, p. 284).
\end{abstract}

Desta forma, por não compreender este ideal dos negros sulistas, a autora desviou-se

para uma interpretação muito peculiar, ao acusar os pais de explorarem suas crianças nesta integração escolar. E, em uma carta enviada a Ellison, reconheceu sua não compreensão deste "ideal de sacrifício" e reviu certos pontos de sua crítica.

Ellison, talvez, queria dizer que os negros sabiam quais eram as dificuldades que passavam, pois, onde estivessem sempre seriam pretos. Assim, por estarem em tal lugar, seriam as pessoas mais adequadas a dizer e a lutar diante do que se passava com elas próprias: "as crianças negras estavam sendo iniciadas com um "ordálio de fogo" na realidade de suas situações violentas" (YOUNG-BRUEHL, 1997, p. 285).

Bodziak Júnior (2017) nos traz um elemento que ajuda a entender a posição primeira de Arendt: houve uma falha em seu exercício de "pensamento representativo" ao não conseguir ver a situação de Little Rock por este ângulo, o "ideal de sacrifício", se colocando no lugar do outro, ainda que sempre tenha buscado ser empática.

Embora Arendt nunca tenha conciliado teoricamente sua compreensão do "ideal de sacrifício" com sua concepção de escola, é possível explorar o encontro destes dois 


\section{Revista \\ Debates Insubmissos}

momentos do pensamento arendtiano através do exercício posto à criança de coerência consigo mesma. [...] pode-se sugerir que um risco para a espontaneidade seria a própria continuidade da segregação legalizada. Reproduzir a tensão e o conflito da segregação racial pela manutenção de leis racistas apenas perpetuaria esta fratura insuportável nas gerações futuras, nas suas comunidades políticas e nas suas instituições. Não atacar esta estrutura perversa seria cometer o erro que Arendt mais abominou na educação, determinar o futuro através da escola. Portanto, o "ideal de sacrifício" pode ser visto como a fórmula encontrada pelos afroamericanos para lidarem com suas capacidades propriamente humanas da espontaneidade, pensamento e da responsabilidade pelo mundo. (BODZIAK JÚNIOR, 2017, p. 69).

Por fim, mesmo recebendo críticas, o texto Reflexões sobre o Little Rock (2004) traz uma importante contribuição para as discussões no terreno pedagógico e teórico-político, a fim de entendermos qual o lugar dos pais e das mães, dos/as professores/as e dos adultos, em geral, face à criação e educação das crianças.

Os educadores deveriam apresentar as crianças ao mundo, dar-lhes instrumentos para compreendê-lo precisa e imparcialmente, de modo que as crianças possam, quando amadurecerem, agir inteligentemente no mundo. (...) Embora concordasse com Ralph Ellison em que um ideal de sacrifício e heroísmo possa ser necessário para crianças vítimas da violência pura e do ódio, desprovidas de pátria, ela considerava tal ideal bem diferente do estudo de swahili e do cultivo de uma ideologia separatista. O que esperava para os filhos dos outros era o que ela própria tivera; tempo para uma boa educação antes que a Judenfrage ("questão judaica") fosse pessoalmente colocada em sua vida e antes que ela, como judia, tivesse que escolher a política. (YOUNG-BRUEHL, 1997, p. 286).

Arendt acreditava que a capacidade de amar o mundo faz com que os adultos não se ausentem da responsabilidade de proteger e apresentar este mesmo mundo aos novos e aos jovens. Esta capacidade de amar, se assim podemos dizer, nos coloca diante da experiência de assumirmos nossos próprios feitos e, politicamente, resolvermos os conflitos que afetam nossas relações enquanto humanos. A reflexão que Arendt fez sobre os acontecimentos de Little Rock deve soar como um convite ao cuidado para com os recém-chegados.

\section{REFERÊNCIAS}

ALMEIDA, Vanessa Sievers. Educação em Hannah Arendt: entre o mundo deserto e o amor ao mundo. São Paulo: Editora Cortez, 2011.

ARENDT, H. Responsabilidade e julgamento. Trad. Rosaura Eichenberg. Edição de Jerome Kohn. São Paulo: Companhia das Letras, 2004. 
ARENDT, Hannah. A condição humana. Trad. Roberto Raposo. Revisão técnica: Adriano Correia. 11 edição. Rio de Janeiro: Editora Forense Universitária, 2014.

ARENDT, Hannah. A crise na educação. In: Entre o passado e o futuro. Trad. Mauro W. Barbosa. $7^{a}$ ed. São Paulo: Perspectiva, 2013. p. 221-247.

ARENDT, Hannah. Entre o passado e o futuro. Trad. Mauro W. Barbosa. $7^{\mathrm{a}}$ ed. São Paulo: Perspectiva, 2013.

ARENDT, Hannah. Origens do totalitarismo: antisemitismo, imperialismo, totalitarismo. Trad. Roberto Raposo. São Paulo: Companhia das Letras, 2000.

ARENDT, Hannah. Reflexões sobre o Little Rock. In: Responsabilidade e julgamento. São Paulo: Companhia das Letras, 2004. p. 160-281.

BODZIAK JÚNIOR, Paulo Eduardo. O impacto do social na educação: Little Rock e o despertar para a responsabilidade em Hannah Arendt. In: CARVALHO, J. S. F.; CUSTÓDIO, C. O. (Org.). Hannah Arendt: a crise na educação e o mundo moderno. São Paulo: Intermeios; FAPESP, 2017. cap. 4, p. 57-70.

CORREIA, Adriano. Hannah Arendt e a modernidade: política, economia e a disputa por uma fronteira. 1. ed. Rio de Janeiro: Forense Universitária, 2014.

GESSAT, Rachel. 1957: Os Nove de Little Rock, set. 2017. Disponível em:

HAYDEN, Patrick. Hannah Arendt: conceitos fundamentais. Trad. José Maria Gomes de Souza Neto. Petrópolis: Editora Vozes, 2020.

MORAES, Eduardo Jardim. Preconceito e política, nov. 2017. Disponível em:

RUSSO, Renato. Índios. Guarulhos: EMI, 1986. Disponível em:

https://www.youtube.com/watch?v=nM_gEzvhsM0\&ab_channel=LegiaoUrbanaVEVO.

Acesso em: 28/04/2019.

YOUNG-BRUEHL, Elizabeth. Hannah Arendt: por amor ao mundo. Rio de Janeiro: elume-

Dumará, 1997.

Sites da Internet

$<$ http://anpof.org/portal/index.php/en/comunidade/coluna-anpof/1365-preconceito-epolitica>. Acesso em: 10 dez. 2018.

<http://www.dw.com/pt-br/1957-os-nove-de-little-rock/a-263358>. Acesso em: 04 jun. 2018.

Recebido: $12 / 12 / 2020$

Aprovado: 14/01/2021 